\title{
EXPERIMENTAL INVESTIGATION OF THE SEISMIC RESPONSE OF A COLUMN ROCKING AND ROLLING ON A CONCAVE BASE
}

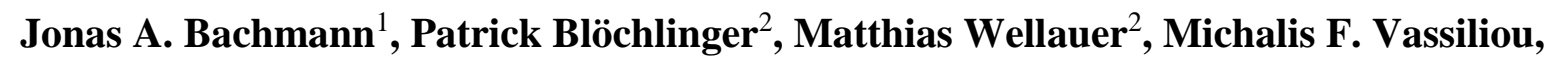 \\ and Božidar Stojadinović
}

\author{
${ }^{1}$ Swiss Federal Institute of Technology (ETH) Zürich \\ Stefano-Franscini-Platz 5, 8093 Zürich, Switzerland \\ e-mail: bachmann@ibk.baug.ethz.ch \\ \{patricbl, wellauem\} @ student.ethz.ch \\ \{vassiliou, stojadinovic\}@ibk.baug.ethz.ch
}

Keywords: Rocking structures, Earthquake Engineering, Experimental Testing, Uplifting Structures

\begin{abstract}
Rocking modifies the seismic response of structures, because uplifting works as a mechanical fuse and limits the forces transmitted to the structure. However, the engineering community is in general reluctant to let a structure uplift because it can overturn, and, more important, an unanchored structure has no redundancy against this failure mode. Using a safety factor for the design of a flat rocking foundation (i.e. designing it larger than minimum required to prevent overturning) goes against the essence of the rocking seismic isolation method, as the structure would end up behaving as fixed to the ground. To protect against overturning but preserve the ability to uplift we propose to extend the flat rocking foundation using curved wedges at its ends. This paper presents the results of dynamic tests of small bodies rocking on curved foundations. The results compare relatively well with the analytical solutions, but they are shown to be very sensitive to the coefficient of restitution.
\end{abstract}




\section{INTRODUCTION}

Since Housner published his seminal paper [1] on rocking of rigid blocks, a plethora of studies on uplifting structures has been published [2-60]. The remarkable property of rocking blocks is that, for a given height to base slenderness ratio, they become more stable as their size increases. There are even cases when out of two columns with the same base, the taller one survived an earthquake while the shorter one did not [60]. It has also been proven that the presence of a cap beam atop of rocking columns, like in the case of the ancient Greek and Roman temples, increases the stability of the system $[12,38,46]$. These results have led researchers to propose rocking as a seismic isolation technique, as the uplift works as a mechanical fuse and limits the forces transmitted to the structures. However, even though some rocking structures have been built in New Zealand [2, 5], the former Soviet Union and Russia [63] and Greece [64], practicing engineers are generally reluctant to apply this method. One reason for that is the lack of codes and simplified methods of analysis. However, this reluctance also stems on the inherent fear of engineers to design unanchored structures that may overturn. Engineers are used to the safety factors, where all the material, geometric, modelling and loading uncertainties are "hidden".

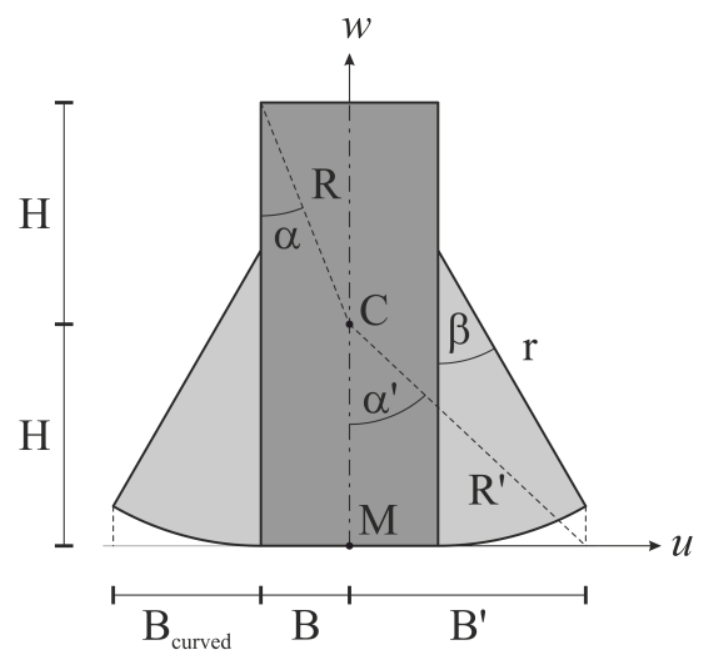

Phase I:

Phase II:
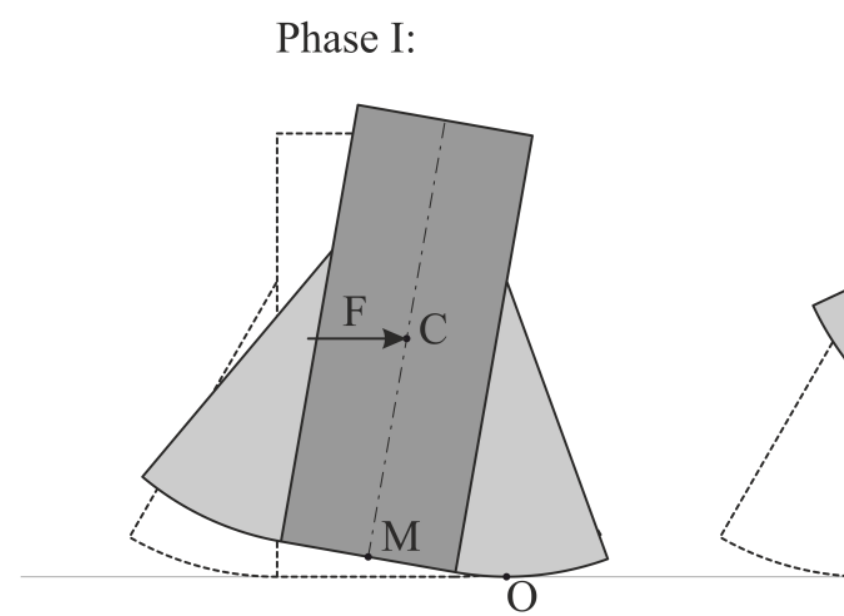

Figure 1. Top: Rigid block with curved wedges - resting position [65]

Bottom: Rigid block with curved wedges - Phase I (rolling) and Phase II (rocking) 
In the case of rocking foundations, when it comes to overturning "resistance", the application of a safety factor would simply mean that the foundation should become larger. This goes against the essence of the rocking seismic isolation method, as the structure would end up behaving as fixed to the ground. To protect against overturning but preserve the ability to uplift we propose to extend the flat rocking foundation using curved wedges at its ends [65] (Figure 1). This paper presents the results of dynamic tests of small bodies rocking on curved foundations. The tests were performed in the ETH Zurich within the semester project of the second and third author. The results compare relatively well with the analytical solutions, but they are shown to be very sensitive to the coefficient of restitution.

\section{REVIEW OF THE ROCKING RESPONSE OF A RIGID BLOCK.}

With reference to Figure 2 and assuming that the coefficient of friction is large enough so that there is no sliding, the equation of motion of a rocking block with size $R=\sqrt{h^{2}+b^{2}}$ and slenderness $\alpha=\arctan (\mathrm{b} / \mathrm{h})$ for rotation around $\mathrm{O}$ and $\mathrm{O}^{\prime}$ respectively is (Yim et al. [3], Makris and Roussos [9], Zhang and Makris [10] among others)

$$
\begin{array}{cc}
I_{O} \ddot{\theta}(t)+m g R \sin [-\alpha-\theta(t)]=-m \ddot{u}_{g}(t) R \cos [-\alpha-\theta(t)], \quad \theta(t)<0 \\
I_{O} \ddot{\theta}(t)+m g R \sin [\alpha-\theta(t)]=-m \ddot{u}_{g}(t) R \cos [\alpha-\theta(t)], \quad \theta(t)>0
\end{array}
$$

Where $I_{o}$ is the moment of inertia of the block around the pivot point.

For rectangular blocks, $I_{O}=(4 / 3) m R^{2}$, and the above equations can be expressed in the compact form

$$
\ddot{\theta}(t)=-p^{2}\left\{\sin [\alpha \operatorname{sgn}(\theta(t))-\theta(t)]+\frac{\ddot{u}_{g}}{g} \cos [\alpha \operatorname{sgn}(\theta(t))-\theta(t)]\right.
$$

The oscillation frequency of a rigid block under free vibration is not constant, because it strongly depends on the vibration amplitude (Housner [1]). Nevertheless, the quantity

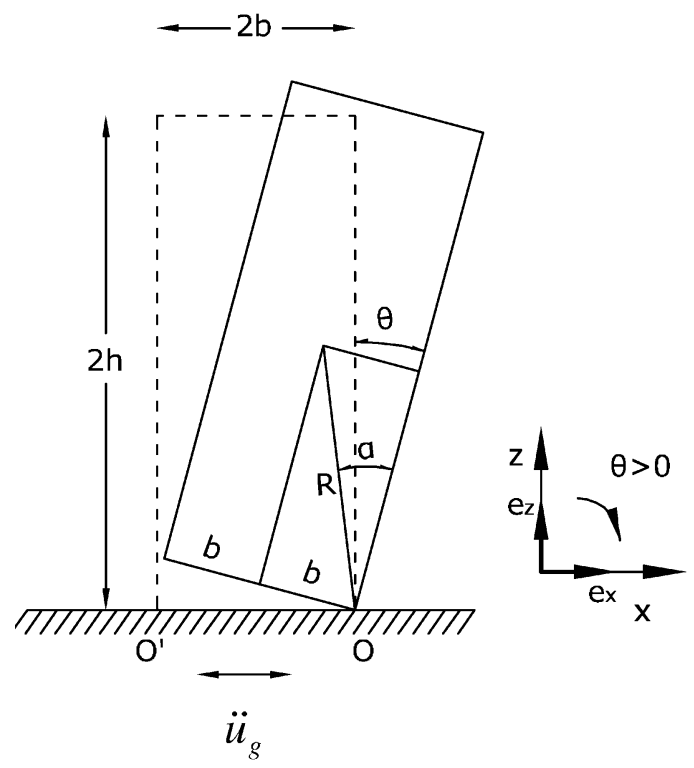

Figure 2. Geometric characteristics of the rocking body model 
$p=\sqrt{\frac{3 g}{4 R}}$ is a measure of the dynamic characteristics of the block. For the $2.0 \mathrm{~m} \times 0.5 \mathrm{~m}$ block shown in Figure 2 (e.g. a modern refrigerator), $p=2.67 \mathrm{rad} / \mathrm{s}$, while $p \approx 8 \mathrm{rad} / \mathrm{s}$ for a typical clay masonry brick. When the angle of rotation reverses, it is assumed that the rotation continues smoothly from points $O$ to $O$ ' and that the impact force is concentrated at the new pivot point, $O^{\prime}$. The ratio of angular velocity after and before the impact is $\varepsilon=\dot{\theta}_{2} / \dot{\theta}_{1}$. Assuming (a) that the impact is instantaneous and (b) that all the impact forces are concentrated at the new pivot point, one can apply conservation of angular momentum about the new pivot point (Housner, [1]). This gives the following coefficient of restitution

$$
\varepsilon=1-\frac{3}{2} \sin ^{2} \alpha
$$
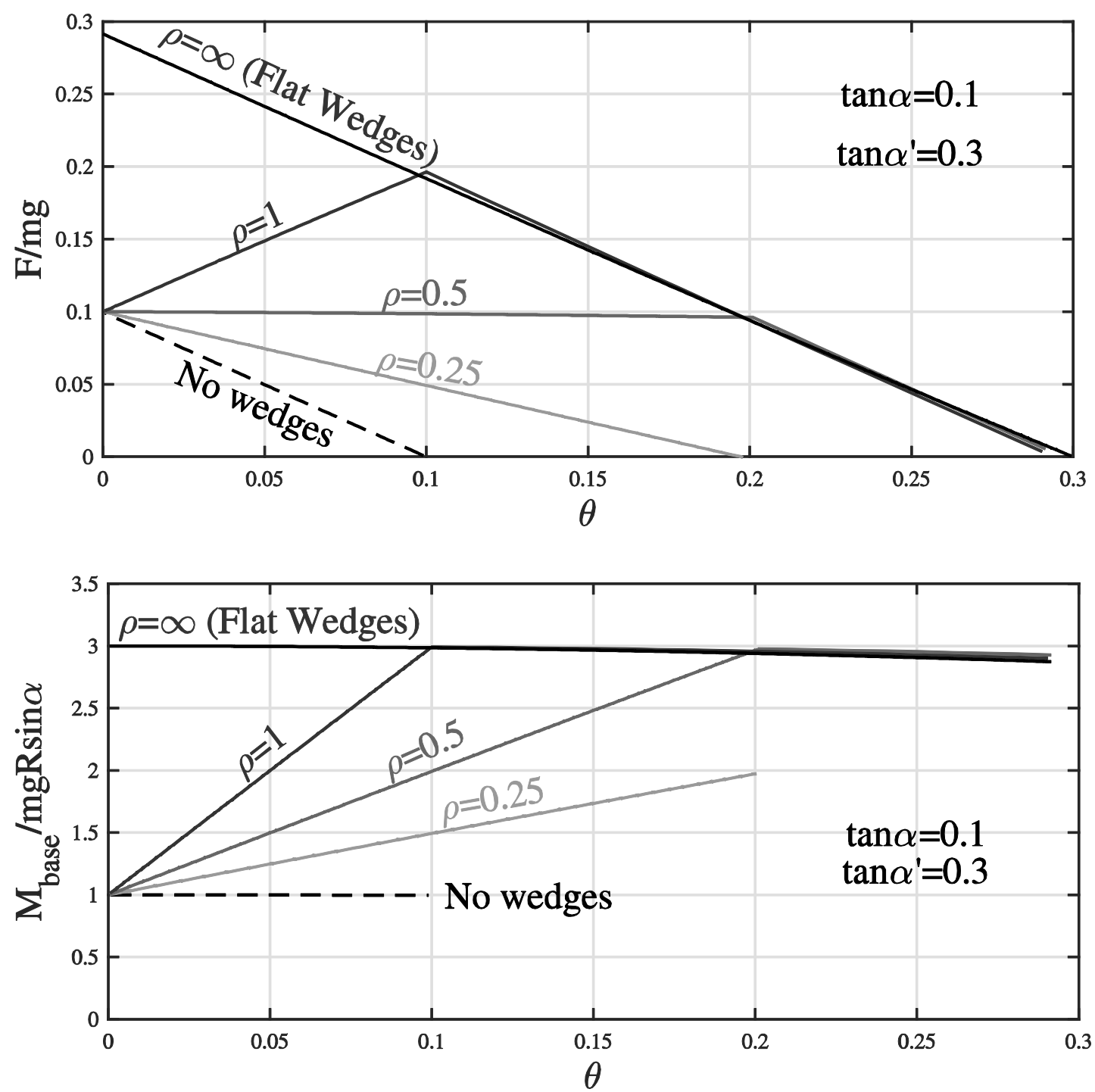

Figure 3 Response of blocks with different wedge curvature. Top: Lateral force - base rotation pushover response curves; Bottom: Base moment - base rotation pushover response curves. 
Under the action of a horizontal force $F$ is applied at the center of mass of the block a rigid block does not displace until the force reaches the uplift equilibrium value. The force - rotation pushover response curve of a rigid block is

$$
F=m g \tan (\alpha-\theta)
$$

It is plotted in Figure 3 (top - dashed line).

The base moment - rotation relationship is given by equation (6)

$$
M_{\text {base }}=m g R \sin a \cos \theta
$$

and is plotted in Figure 3 (bottom - dashed line).

It is evident that the block has negative post-uplift stiffness while the base moment stays almost constant. An extensive discussion on the significance of the negative post-uplift stiffness is offered in Makris and Vassiliou [47] and Vassiliou and Makris [58]

\section{ROLLING AND ROCKING RESPONSE OF A BLOCK ON A BASE WITH CURVED ENDS}

This section presents the model of a rigid block rocking and rolling on an extended curved base [65] (Figure 3) and briefly discusses its properties. An extended presentation of the above model and the numerical study of tis properties under seismic excitation is a subject of ongoing research and lies beyond the scope of this paper.

The geometric properties of the block are shown on Figure 1. The added wedges are characterized by their radius of curvature $r$ and by their angle $\beta$. The curved wedges are assumed to be massless. When a horizontal force is applied to the center of mass of the block, the block stays initially at rest until the load reaches the critical value of $m g \tan (\alpha)$. Next, the block rolls on the curved surface (Phase I) until the tilt angle reaches the value $\beta$. Phase II follows where the block rocks, i.e. rotates around the edge of the curved base. The force deformation relationships for the different cases are given in equations (7) and (8) (for positive $\theta$ ):

Phase I-Rolling:

$$
F=m g \frac{\sin (\alpha-\theta)+2 \rho \cos \alpha \sin \theta}{\cos (\alpha-\theta)+2 \rho \cos \alpha(1-\cos \theta)}, \quad \theta<\beta
$$

Phase II - Rocking:

$$
F=m g \frac{\sin (\alpha-\theta)+2 \rho \cos \alpha(\sin (\beta-\theta)+\sin \theta)}{\cos (\alpha-\theta)+2 \rho \cos \alpha(\cos (\beta-\theta)-\cos \theta)}, \quad \theta>\beta
$$

where $\rho$ is the normalized wedge radius of curvature:

$$
\rho=\frac{r}{2 H}
$$

Linearization of the above equations gives:

Phase I-Rolling:

$$
F=m g(\alpha+(2 \rho-1) \theta), \quad \theta<\beta
$$

Phase II-Rocking:

$$
F=m g(\alpha+2 \rho \beta-\theta), \quad \theta>\beta
$$


Therefore, the post-uplift stiffness of the rolling phase is positive, if $\rho>0.5$, and negative, if $\rho<0.5$.

The base moment is equal to

Phase I-Rolling:

$$
\frac{M_{\text {base }}}{m g R \sin \alpha}=\cos \theta+2 \rho \cot \alpha \sin \theta, \quad \theta<\beta
$$

Phase II-Rocking:

$$
\frac{M_{\text {base }}}{m g R \sin \alpha}=\cos \theta+2 \rho \cot \alpha(\sin (\beta-\theta)+\sin \theta), \quad \theta>\beta
$$

Linearization of the above equations gives:

Phase I-Rolling:

$$
M_{\text {base }}=m g(B+r \theta), \quad \theta<\beta
$$

Phase II - Rocking:

$$
M_{\text {base }}=m g\left(B+B_{\text {curved }}\right), \quad \theta>\beta
$$

The $F-\theta$ and the $M_{\text {base }}-\theta$ pushover response curves are shown in Figure 3. The post-uplift stiffness in Phase I depends on the curvature of the curved part of the base and can lie anywhere from negative to positive, resembling the behavior of the restrained rocking column presented in [58]. Overturning can occur either in the rocking phase, or in the rolling phase (when the wedge curvature is relatively large, e.g. case $\rho=0.25$ in Figure 3).

The equation of motion for the Phase I is:

$$
\left.\ddot{\theta}=\frac{\left(\begin{array}{c}
-\frac{3}{2} \rho \cos \alpha \dot{\theta}^{2}(\sin ( \pm a-\theta)+2 \rho \cos \alpha \sin \theta)- \\
-p^{2}\left(\sin ( \pm \alpha-\theta)+2 \rho \cos \alpha \sin \theta+\frac{\ddot{u}_{g}}{g}(\cos ( \pm \alpha-\theta)+2 \rho \cos \alpha(1-\cos \theta))\right)
\end{array}\right)}{\left(\frac{3}{4}+\frac{I_{c}}{\frac{4}{3} m_{c} R^{2}}+6 \rho^{2} \cos ^{2} \alpha(1-\cos \theta)+3 \rho \cos \alpha(\cos ( \pm \alpha-\theta)-\cos \alpha)\right.}\right)
$$

and for the phase II it is:

$$
\left.\ddot{\theta}=-p^{2}\left(\begin{array}{c}
\sin ( \pm \alpha-\theta)+2 \rho \cos \alpha(\sin ( \pm \beta-\theta)+\sin \theta)+ \\
+\frac{\ddot{u}_{g}}{g}(\cos ( \pm \alpha-\theta)+2 \rho \cos \alpha(\cos ( \pm \beta-\theta)-\cos \theta)) \\
\left(\frac{3}{4}+\frac{I_{c}}{\frac{4}{3} m_{c} R^{2}}+6 \rho^{2} \cos ^{2} \alpha(1-\cos \beta)+3 \rho \cos \alpha(\cos (\alpha-\beta)-\cos \alpha)\right.
\end{array}\right)\right)
$$

where $p$ is defined as in the case of a rectangular rocking block: 


$$
p=\sqrt{\frac{3 g}{4 R}}
$$

$\rho$ is the normalized radius of curvature:

$$
\rho=\frac{r}{2 H}
$$

$I_{c}$ is the moment of inertia of the system around its center of mass. In order to take into account the mass of the wedges, they need to be accounted for in the computation of $I_{c}$.

Following Housner, it is assumed that at each impact is instantaeous and that all the impact forces are concentrated at the new pivot point (i.e. at a distance $B$ from the axis of symmetry), the coefficient of restitution is:

$$
\varepsilon=\frac{\dot{\theta}_{\text {post-impact }}}{\dot{\theta}_{\text {pre-impact }}}=1-\frac{2 m R^{2}}{m R^{2}+I_{c}} \sin ^{2} a
$$

If the wedges are assumed massless the coefficient of restutition is given by the well known Housner coefficient:

$$
\varepsilon=\frac{\dot{\theta}_{\text {post-impact }}}{\dot{\theta}_{\text {pre-impact }}}=1-\frac{3}{2} \sin ^{2} a
$$

It is evident that according to the above assumptions the coefficient of restitution, and hence the damping, are controlled only by the slederness ratio, $\alpha$, and are not influenced by the wedges.

\section{FREE VIBRATION TESTS OF A RIGID COLUMN WITH CURVED WEDGES}

\subsection{Specimens and test setup}

A specimen consists of two columns (C), two link plates (L) and four changeable feet $(\mathrm{F})$, all made of aluminium (Figures 4, 5 and 6). Two linked columns (instead of one) were used to avoid out-of-plane motion. The top feet were used because the specimens will be used in the future to test the response of a rocking frame on columns with curved end. For the tests presented herein, the top feet are obsolete and only result to the center of gravity being at column mid-height.

The total height of all the specimens is $2 \mathrm{H}=500 \mathrm{~mm}$. The horizontal projection of the curved feet $\left(2 \times\left(B_{\text {curved }}+B\right)\right)$ is identical in all specimens and equal to $150 \mathrm{~mm}$, giving $\tan \left(\alpha^{\prime}\right)=150 / 500=0.3$. Two groups of specimens are examined: One with a flat base equal to $2 \mathrm{~B}=50 \mathrm{~mm}(\tan (\alpha)=0.1)$ and one with a flat base equal to $2 \mathrm{~B}=75 \mathrm{~mm}(\tan (\alpha)=0.15)$. In each group, 4 different curvatures of the curved part are tested: flat, $r=\{500 \mathrm{~mm}, 250 \mathrm{~mm}$, $125 \mathrm{~mm}\}$. For the curved specimens $\rho=r / 2 \mathrm{H}=\{1,0.5,0.25\}$. These curvatures correspond to a positive, zero and negative post-uplift stiffness. These geometrical properties of the specimens are sketched in Figure 7 and are summarized (together with the specimen masses) in Table 1. 


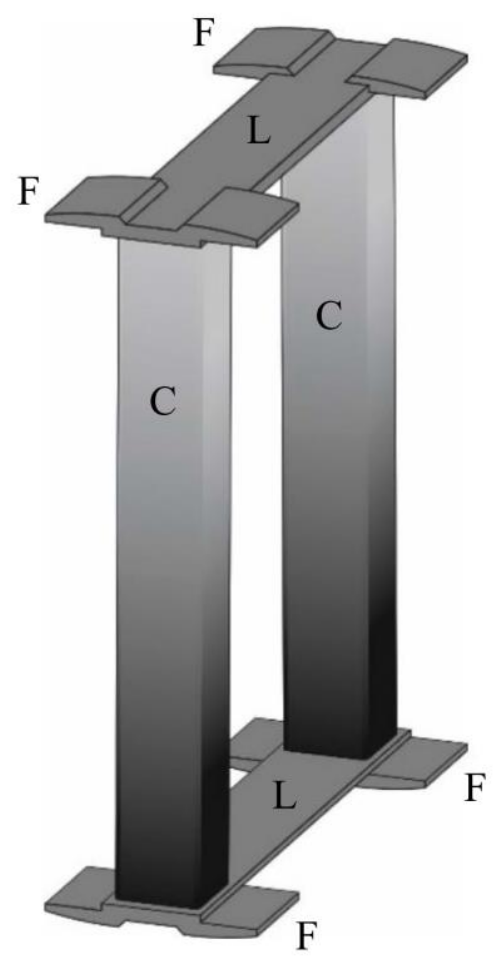

Figure 4. Sketch of a specimen and ist components

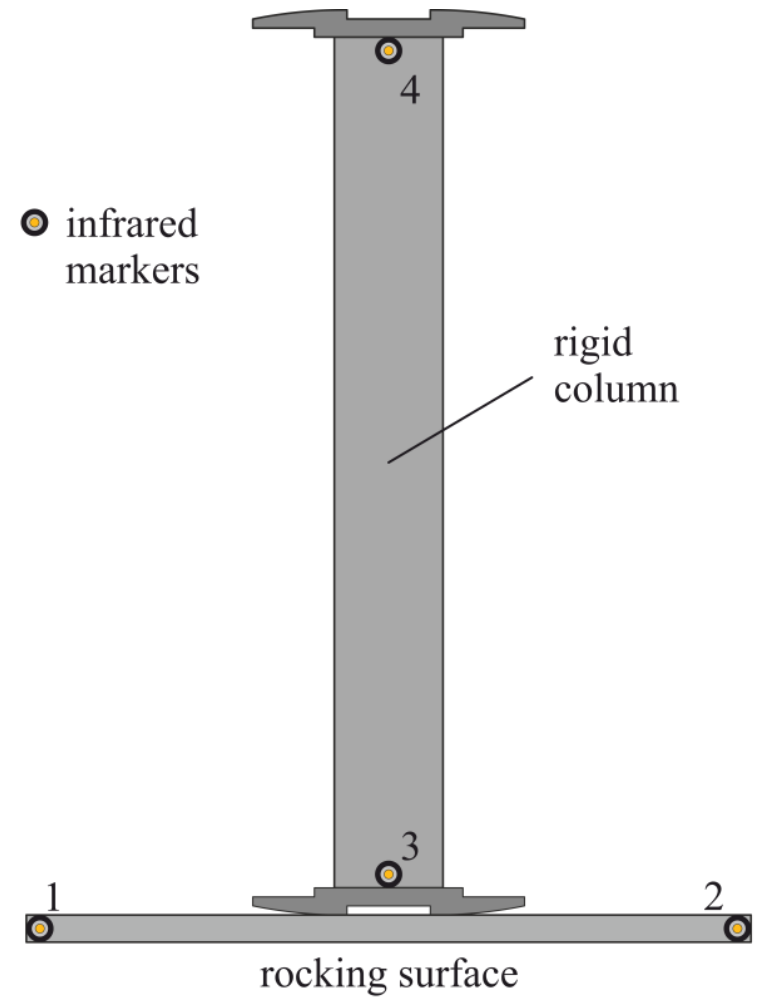

Figure 5. Position of infrared markers

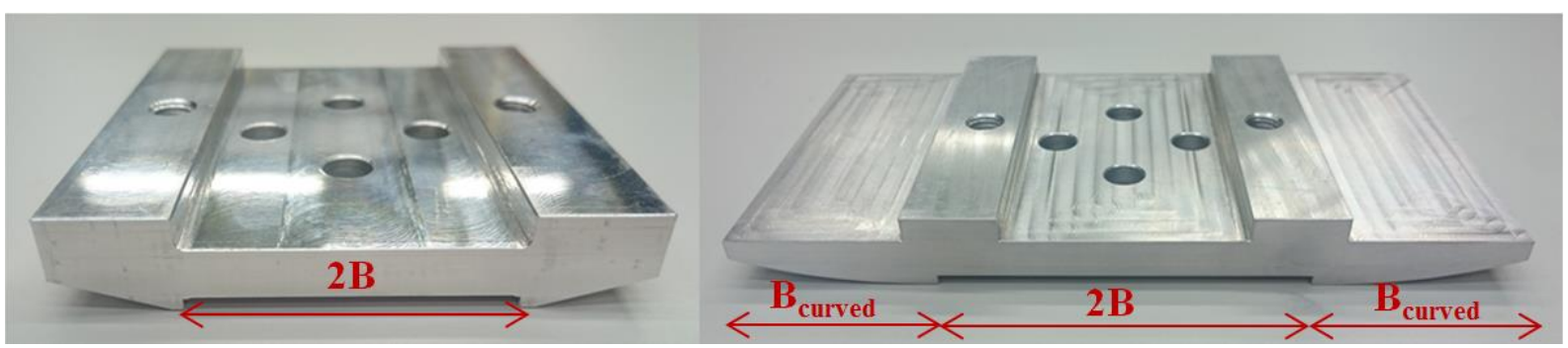

Figure 6. Flat foot (left) and curved foot (right)

\begin{tabular}{|c|c|c|c|c|c|c|c|c|c|c|c|}
\hline & $\begin{array}{c}2 \mathrm{H} \\
{[\mathrm{mm}]}\end{array}$ & $\begin{array}{c}2 B+2 B_{\text {curved }} \\
{[\mathrm{mm}]}\end{array}$ & $\begin{array}{c}2 B \\
{[\mathrm{~mm}]}\end{array}$ & $\begin{array}{l}B_{\text {curved }} \\
\text { [mm] }\end{array}$ & $\begin{array}{c}\tan \alpha^{\prime} \\
{[-]}\end{array}$ & $\begin{array}{c}\tan \alpha \\
{[-]}\end{array}$ & $\begin{array}{c}r \\
{[\mathrm{~mm}]}\end{array}$ & $\begin{array}{c}\rho \\
{[-]}\end{array}$ & $\begin{array}{l}\boldsymbol{\beta} \\
{[-]}\end{array}$ & $\begin{array}{c}m_{c} \\
{[\mathrm{~kg}]}\end{array}$ & $\begin{array}{c}I_{c} \\
{\left[\mathrm{~kg} \mathrm{~mm}^{2}\right]}\end{array}$ \\
\hline 1 & 500 & 150 & 50 & - & 0.3 & 0.1 & - & - & - & 5.717 & $229^{\prime} 662$ \\
\hline 2 & 500 & 150 & 50 & 50 & 0.3 & 0.1 & 500 & 1 & 0.100 & 6.331 & $266 \cdot 897$ \\
\hline 3 & 500 & 150 & 50 & 50 & 0.3 & 0.1 & 250 & 0.5 & 0.201 & 6.255 & $262 ‘ 445$ \\
\hline 4 & 500 & 150 & 50 & 50 & 0.3 & 0.1 & 125 & 0.25 & 0.412 & 6.391 & $270^{\prime} 442$ \\
\hline 5 & 500 & 150 & 75 & - & 0.3 & 0.15 & - & - & - & 5.737 & $230^{\circ} 171$ \\
\hline 6 & 500 & 150 & 75 & 37.5 & 0.3 & 0.15 & 500 & 1 & 0.075 & 6.328 & $267^{\prime} 254$ \\
\hline 7 & 500 & 150 & 75 & 37.5 & 0.3 & 0.15 & 250 & 0.5 & 0.151 & 6.287 & $265^{\prime} 393$ \\
\hline 8 & 500 & 150 & 75 & 37.5 & 0.3 & 0.15 & 125 & 0.25 & 0.305 & 5.717 & $261^{\prime} 459$ \\
\hline
\end{tabular}

Table 1: Geometric characteristics of the specimens 

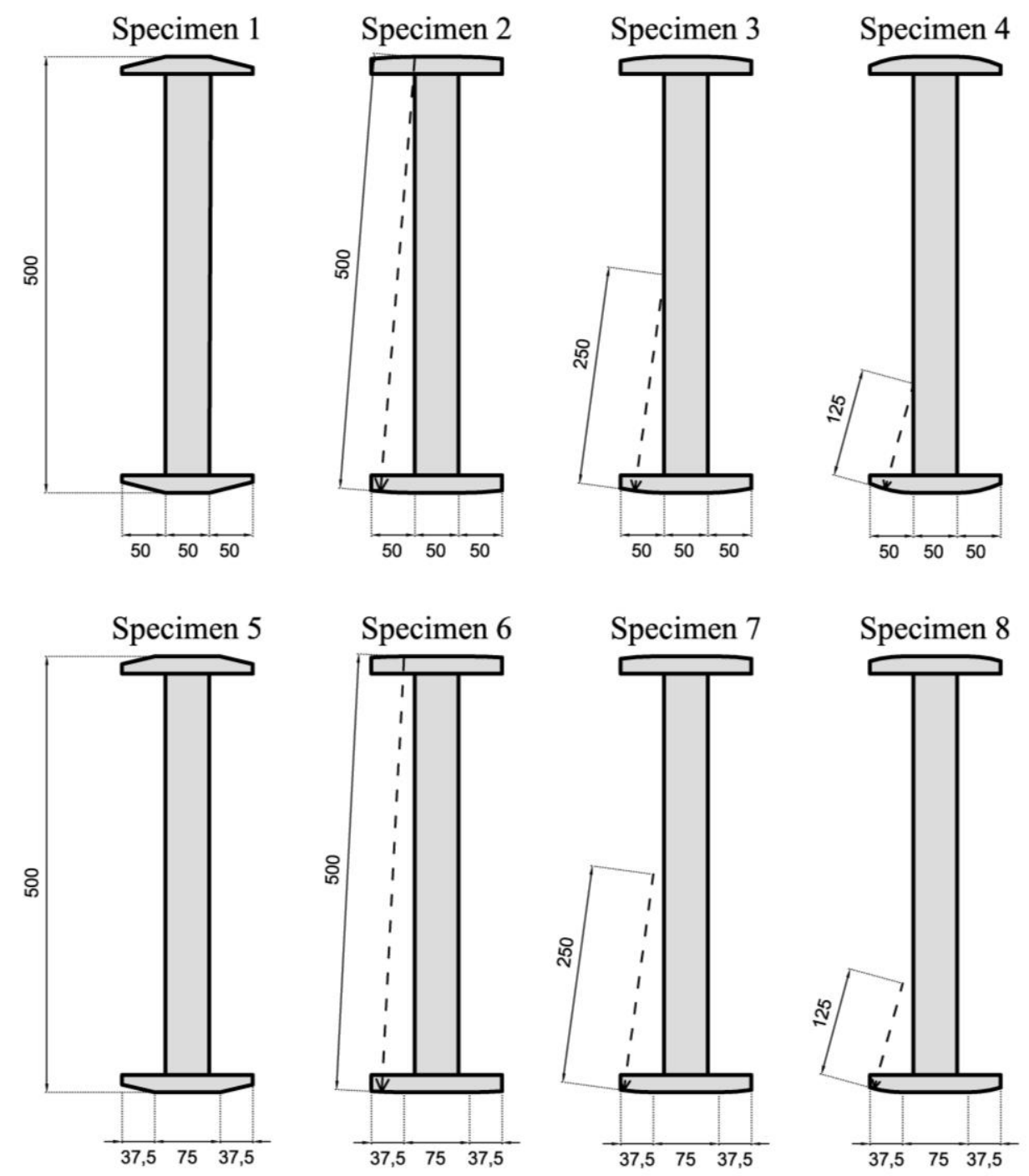

Figure 7. Geometric characteristics of the specimens.

\subsection{Test Method}

The specimens were tested on a flat, horizontal aluminium plate. They were tilted to an initial tilting angle and were let to move freely. The entire response time history was recorded, but in order to avoid experimental error due to potential unintended initial velocity, the time history was post processed and only the part after the maximum following the first impact was kept and later compared with the numerical solution.

\subsection{Data Acquisition System}

An Optotrak Certus System, manufactured by Northern Digital Inc., was used to track the position of the specimens during the tests. This system uses active infrared-emitting diodes as markers and a trinocular camera system to determine the position of the markers. In order to measure the tilt angle $\theta(t)$ and a potential slip on impact, four light-emitting diodes (LED) were used: two of them were placed on the rigid plate the structure was rocking on, a third one is positioned at the base, and the fourth one on top of the column (Figure 5). The NDI camera was able to compute the 3D angle between the LED 1-2 line and the LED 3-4 line as 
well as the relative displacement between LED 1 and 3. The experimental design is shown in Figure 8 .

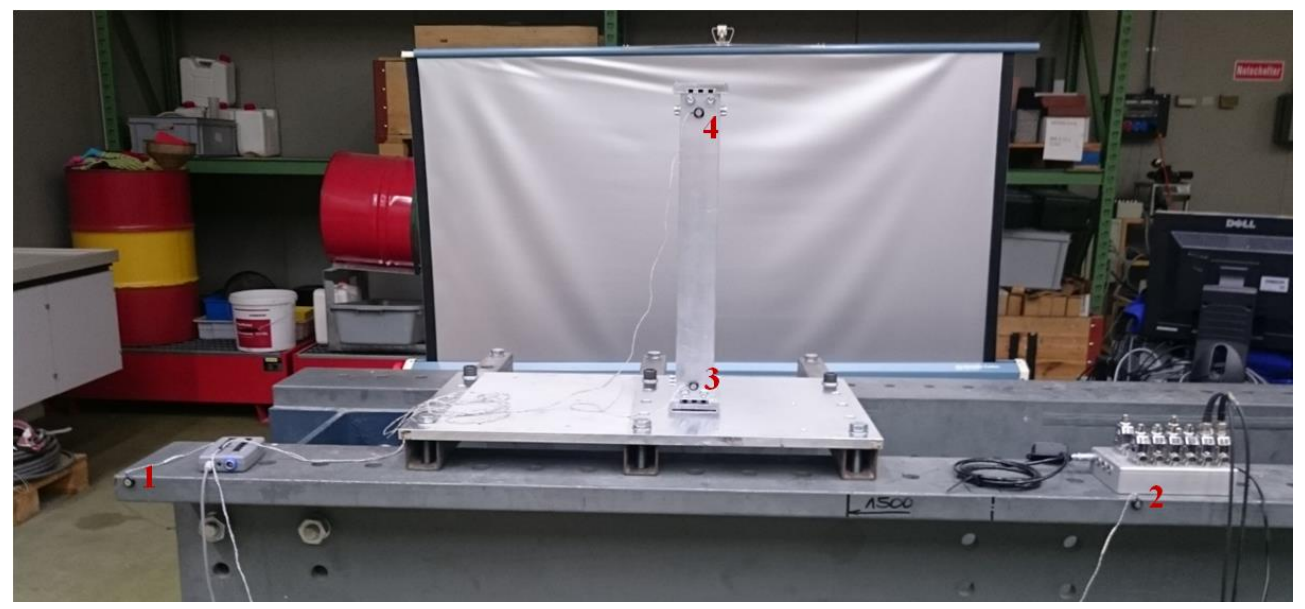

Figure 8. Experimental design

The accuracy of the system was determined by measuring the position of a marker at rest over a long period of time. In the $\mathrm{x}$ - and $\mathrm{y}$-directions in the plane where rocking motion takes place, the accuracy was about $0.02 \mathrm{~mm}$. In the z-direction, perpendicular to the plane of motion, the accuracy was about $0.10 \mathrm{~mm}$. The position sampling frequency was $500 \mathrm{~Hz}$.

\subsection{Results and comparison with numerical solution}

The objective of the experimental campaign was to validate the analytical model presented in the previous section. Each specimen was tested three times: 24 tests were performed. Figures 9-16 plot the time histories of the normalized tilt angle, $\theta / \alpha$. Three time histories are ploted in each plot: (a) the experiment results, (b) the numerical solution with the theoretical (Housner) coefficient of restitution, and (c) the numerical solution with an empirical coefficient of restitution. The empirical coefficient of restitution was obtained from the first 10 motion cycles assuming that energy dissipation takes place only at impact.

One can observe:

1) Hounser assumptions give a good estimate of the coefficient of restitution. For example, in Setup 1 the experimental value is $\varepsilon_{e m p}=0.990$ while Housner assumptions would give $\varepsilon_{t h}=0.988$. In terms of normalized energy loss per impact, the empirical coefficient would give $1-\varepsilon_{\text {emp }}^{2}=1.99 \%$ while Housner would give $1-\varepsilon_{t h}^{2}=2.39 \%$. Considering the complicated nature of impact and damping, an accuracy of $20 \%$ is a good approximation.

2) Hounser-like coefficients of restitution slightly overestimate energy dissipation for the specimens without curved wedges (Specimens 1 and 5). In an effort to explore the source of this deviation, one has to explore Housner assumptions: (a) the impact is instantaneous, and (b) all the impact forces are concentrated on the new pivot point. Assumption (a) allows for the typical assumption that the non-impact forces (in this case the weight) can be neglected during the application of the impulsemomentum theorem. Assumption (b) leads to the Conservation of Angular Momentum Theorem (CAMT) applied about the new pivot point. Else, the CAMT should be applied about the point where the resultant of the impact forces is acting. Since 
the bodies are rigid, the impact is expected to be instantaneous (and the weight is expected to be much smaller than the impact forces), at least for relatively large velocity impacts. On the other hand back-calculations for Specimen 1 show that the slight difference between the experimentally observed and the Hounser coefficient of restitution means that the point of action of the force should be $0.2 \mathrm{~mm}$ away from the new pivot point. Missing the point of application of the resultant of the impact forces by only $0.2 \mathrm{~mm}$ (which corresponds to $0.4 \%$ of the base) shows that Housner assumptions are valid and reasonable.

3) The addition of the curved wedges reverses the situation: Hounser assumptions underestimate the energy loss consistently (with the exception of Specimen 6). It seems that the addition of the wedges shifts the point of action of the impact forces away from the axis of symmetry, hence increasing the energy dissipation. However, apart from stating that qualitative result, it is impossible to quantify the increase.

4) In general, the coefficient of restitution decreases (implying a larger damping ratio) for low velocity impacts. This explains why a rocking block does not need infinite number of impacts to stop, as Hounser assumptions would predict [66] and is consistent with the results presented in [23]. Evidently, for smaller velocity impacts, the weight of the specimen is not negligible when compared to the impact forces and Hounser assumption (a) does not hold: The weight contributes to the impulsemomentum equation and slows down the motion.

5) Even though the coefficient of restitution is predicted relatively well, in many cases the numerical solutions diverge from the experiment data (e.g. become out of phase with the experiment data). Unlike elastic viscously-damped systems (where the period and the damping are only loosely related $-\omega_{d}=\omega_{n} \sqrt{1-\zeta^{2}}$ ) the ,period“ or a rocking column (i.e. twice the time interval between two impacts) strongly depends on damping. This is attributed to the dependence of the period on the amplitude of vibration (hence on the coefficient of restitution). The above observation explains the difficulties in predicting the seismic response of a rigid block to a specific time history [56] and urges for a stochastic treatment of the rocking problem. It is evident that if deviations of $0.2 \mathrm{~mm}$ in the prediction of the location of the impact point lead to different time history results, an error or $0.4 \%$ of the flat part of the foundation, then the deterministic treatment of the rocking problem is impossible.

\section{CONCLUSIONS}

Curved wedges are added to the flat base of a rocking rigid column in order to increase its overturning stability without significantly increasing the base moment. The equations of motion were derived and validated against free-vibration tests. It is shown that the theoretical values for the coefficient of restitution are numerically close to the experimentally obtained values. However, the response of the block is so sensitive to the exact coefficient of restitution value that a deterministic calculation of the response to a ground motion becomes practically impossible. 

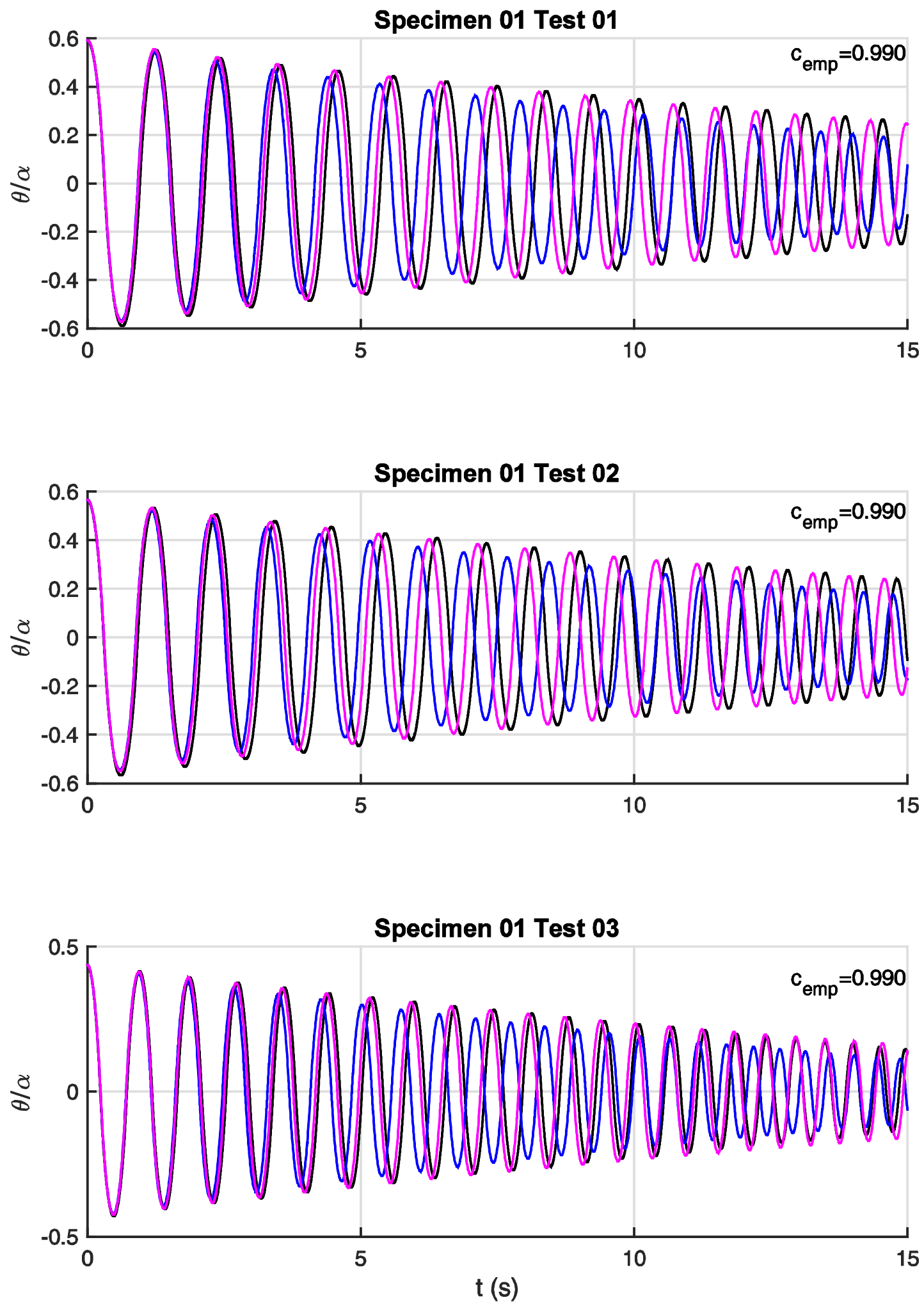

- Experimental $\longrightarrow$ Numerical (Housner) $\longrightarrow$ Numerical (empirical)

$\tan (\alpha)=0.1 \quad \tan \left(\alpha_{\mathrm{p}}\right)=0.1 \quad \rho=\infty \quad \mathrm{l}_{\mathrm{c}}=229662 \mathrm{~kg} \mathrm{mm^{2 }} \quad \mathrm{m}=5.717 \mathrm{~kg} \quad \mathrm{c}_{\mathrm{th}}=0.988$

Figure 9. Normalized tilt angle, $\theta / \alpha$, time history for Specimen 1 

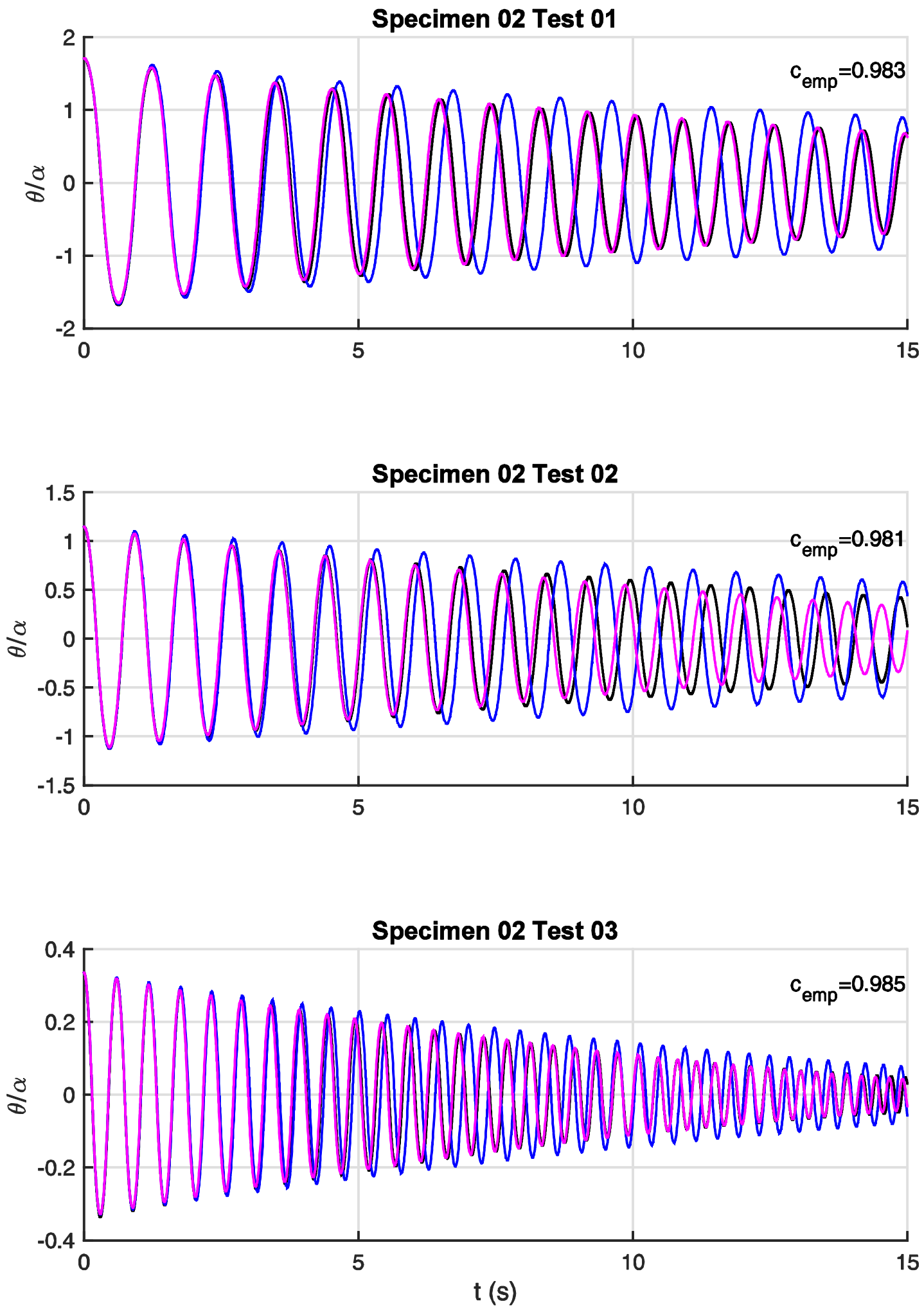

- Experimental $\longrightarrow$ Numerical (Housner) Numerical (empirical)

$\tan (\alpha)=0.1 \quad \tan \left(\alpha_{\mathrm{p}}\right)=0.3 \quad \rho=1 \quad \mathrm{I}_{\mathrm{c}}=266897 \mathrm{~kg} \mathrm{~mm}^{2} \quad \mathrm{~m}=6.331 \mathrm{~kg} \quad \mathrm{c}_{\mathrm{th}}=0.988$

Figure 10. Normalized tilt angle, $\theta / \alpha$, time history for Specimen 2 

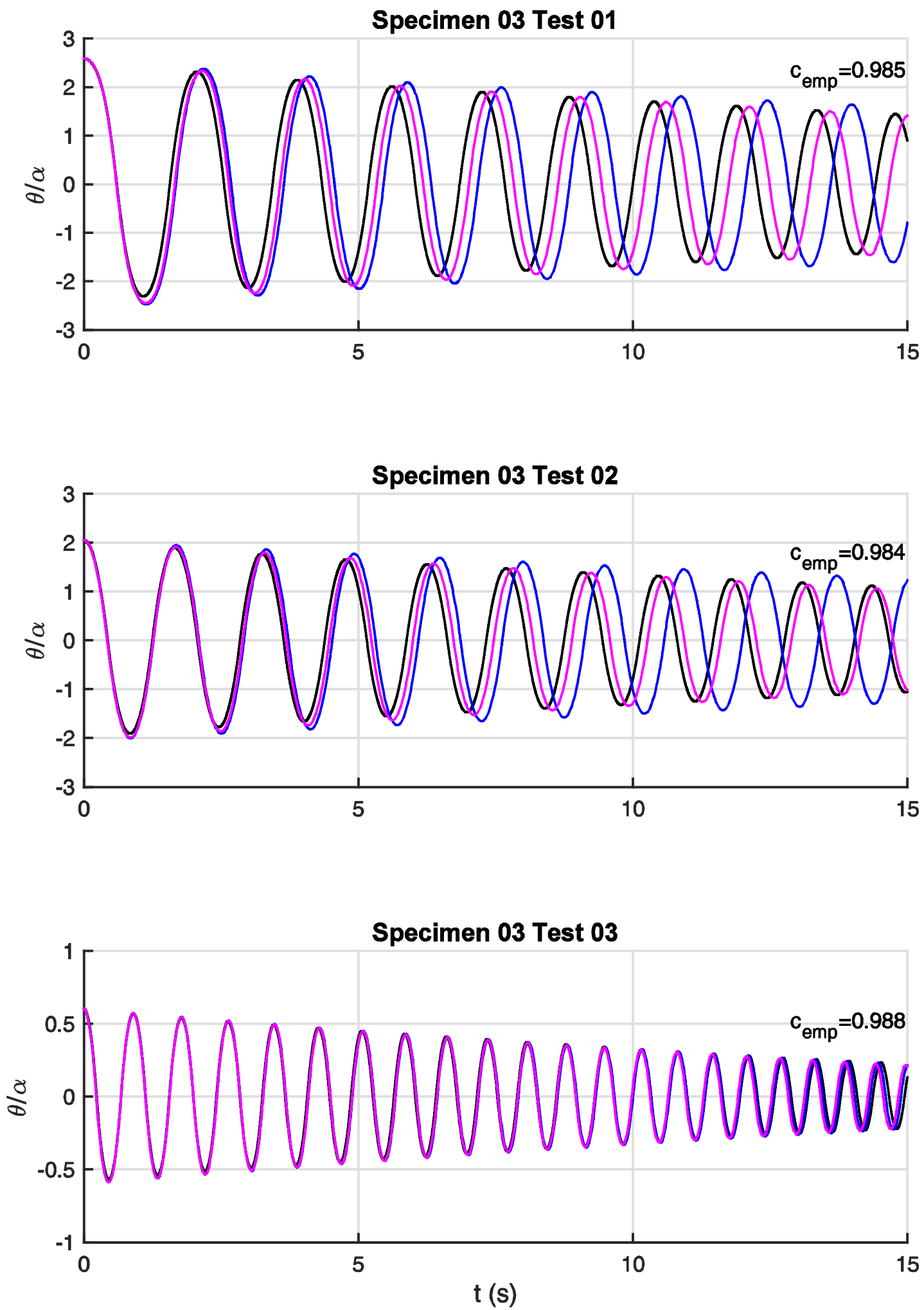

- Experimental — Numerical (Housner) - Numerical (empirical)

$\tan (\alpha)=0.1 \quad \tan \left(\alpha_{\mathrm{p}}\right)=0.3 \quad \rho=0.5 \quad \mathrm{I}_{\mathrm{c}}=262445 \mathrm{~kg} \mathrm{~mm} \mathrm{~m}^{2} \quad \mathrm{~m}=6.255 \mathrm{~kg} \quad \mathrm{c}_{\mathrm{th}}=0.988$

Figure 11. Normalized tilt angle, $\theta / \alpha$, time history for Specimen 3 

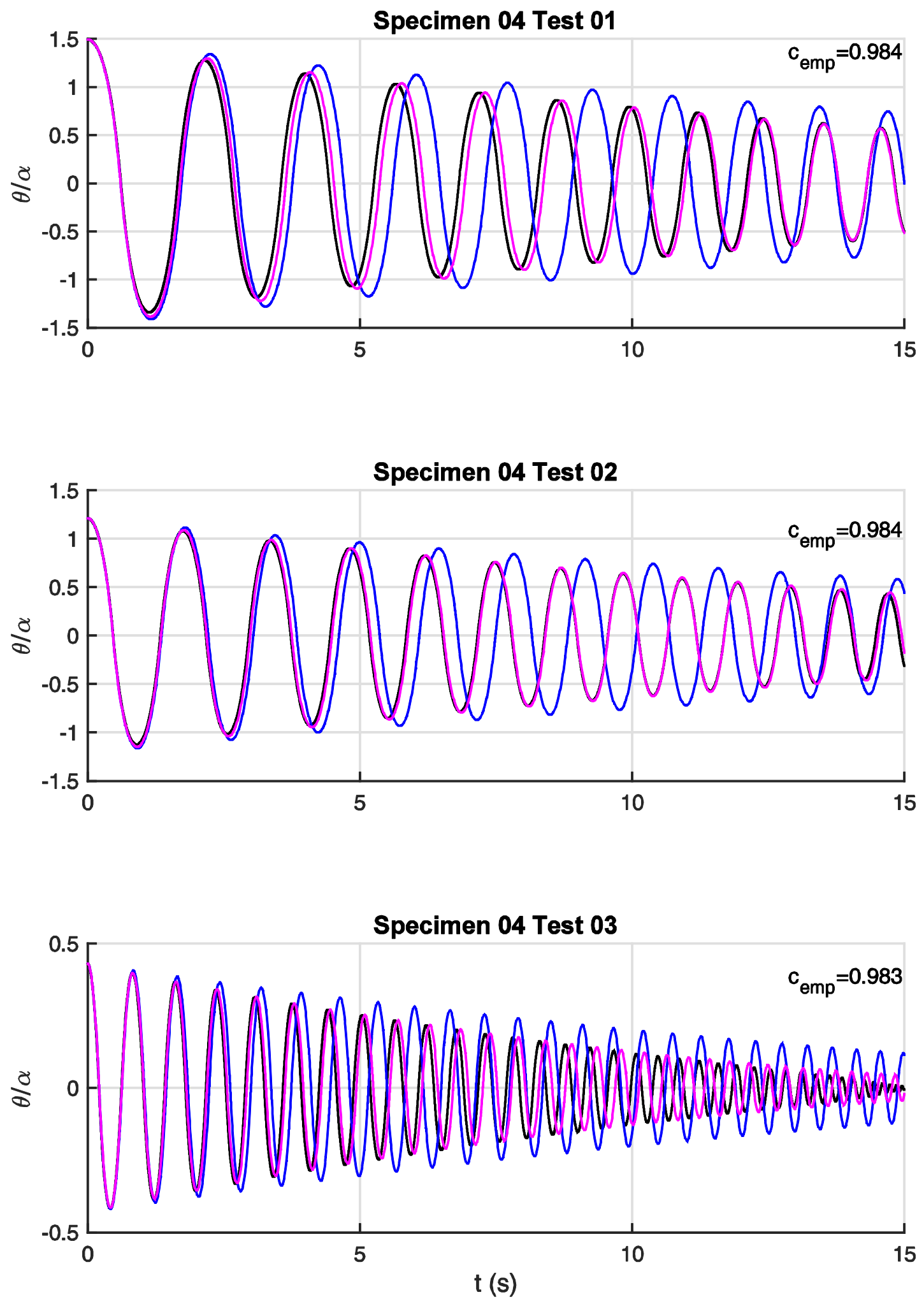

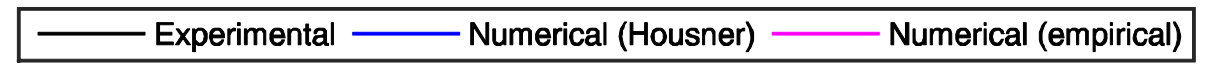

$\tan (\alpha)=0.1 \quad \tan \left(\alpha_{\mathrm{p}}\right)=0.3 \quad \rho=0.25 \quad \mathrm{I}_{\mathrm{c}}=270442 \mathrm{~kg} \mathrm{mm^{2 }} \quad \mathrm{m}=6.391 \mathrm{~kg} \quad \mathrm{c}_{\mathrm{th}}=0.988$

Figure 12. Normalized tilt angle, $\theta / \alpha$, time history for Specimen 4 

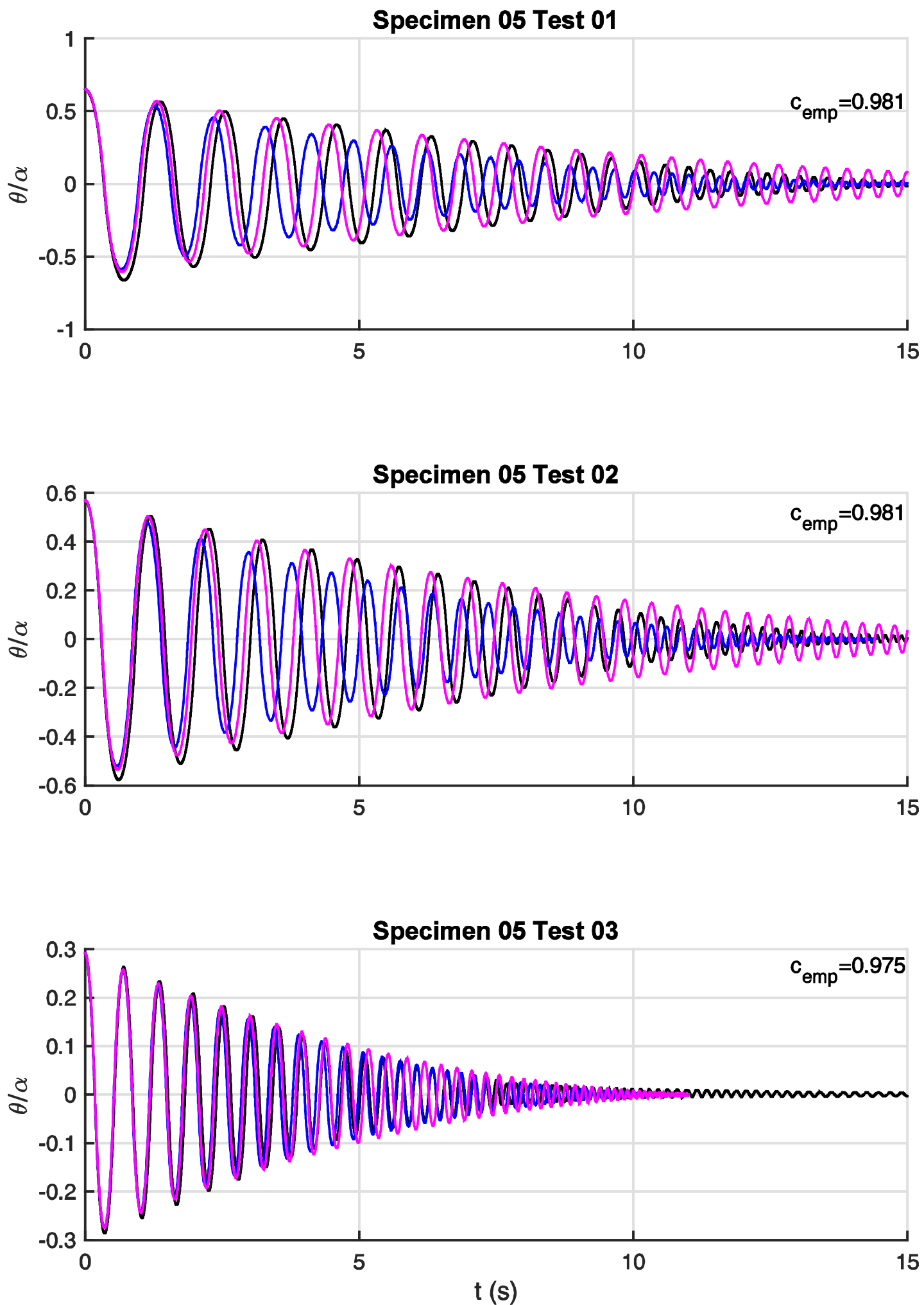

- Experimental $\longrightarrow$ Numerical (Housner) $\longrightarrow$ Numerical (empirical)

$\tan (\alpha)=0.15 \quad \tan \left(\alpha_{\mathrm{p}}\right)=0.15 \quad \rho=\infty \quad \mathrm{I}_{\mathrm{c}}=230171 \mathrm{~kg} \mathrm{~mm}^{2} \quad \mathrm{~m}=5.737 \mathrm{~kg} \quad \mathrm{c}_{\mathrm{th}}=0.973$

Figure 13. Normalized tilt angle, $\theta / \alpha$, time history for Specimen 5 

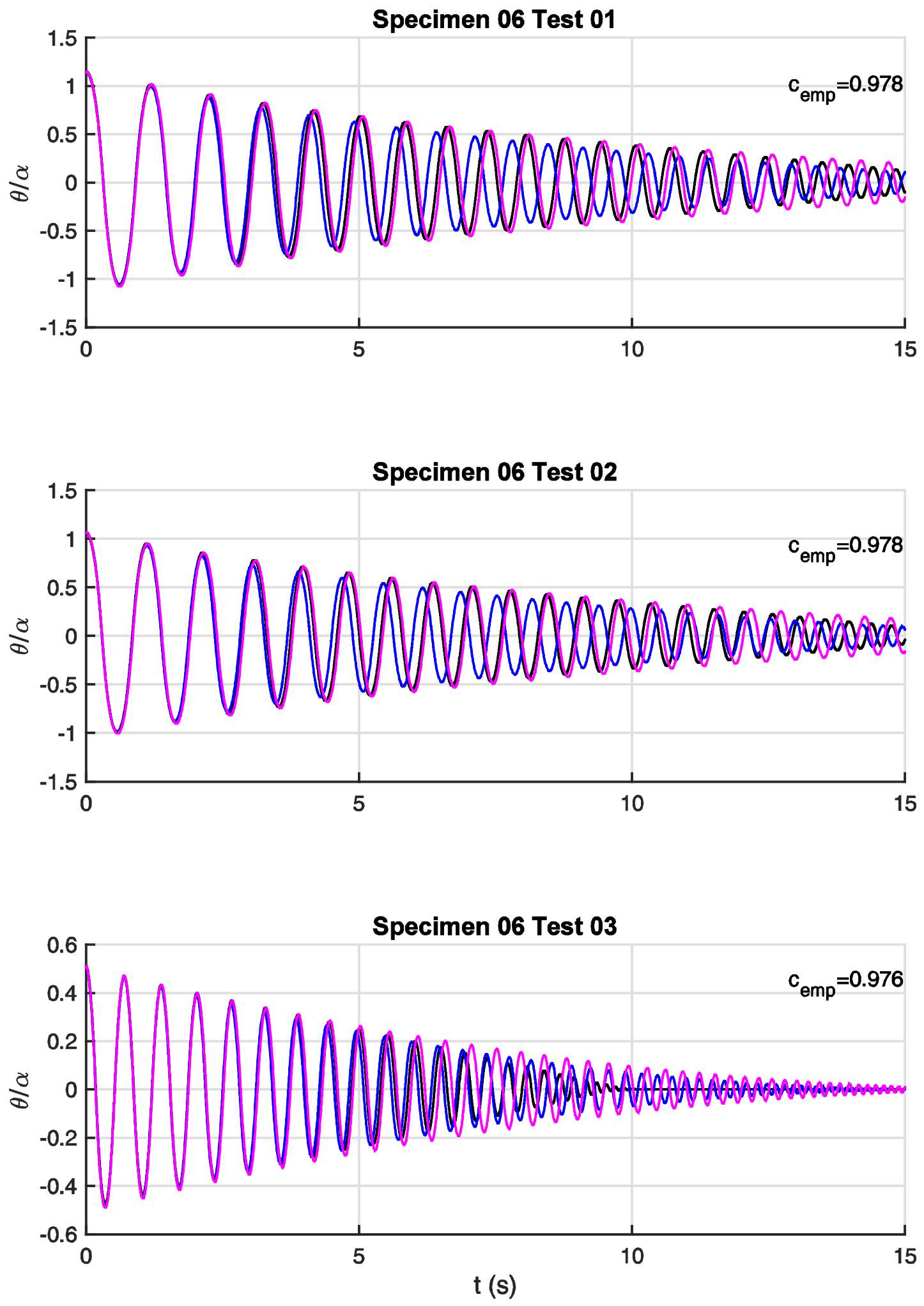

- Experimental — Numerical (Housner) Numerical (empirical)

$\tan (\alpha)=0.15 \quad \tan \left(\alpha_{\mathrm{p}}\right)=0.3 \quad \rho=1 \quad \mathrm{I}_{\mathrm{c}}=267254 \mathrm{~kg} \mathrm{mm^{2 }} \quad \mathrm{m}=6.328 \mathrm{~kg} \quad \mathrm{c}_{\mathrm{th}}=0.974$

Figure 14. Normalized tilt angle, $\theta / \alpha$, time history for Specimen 6 

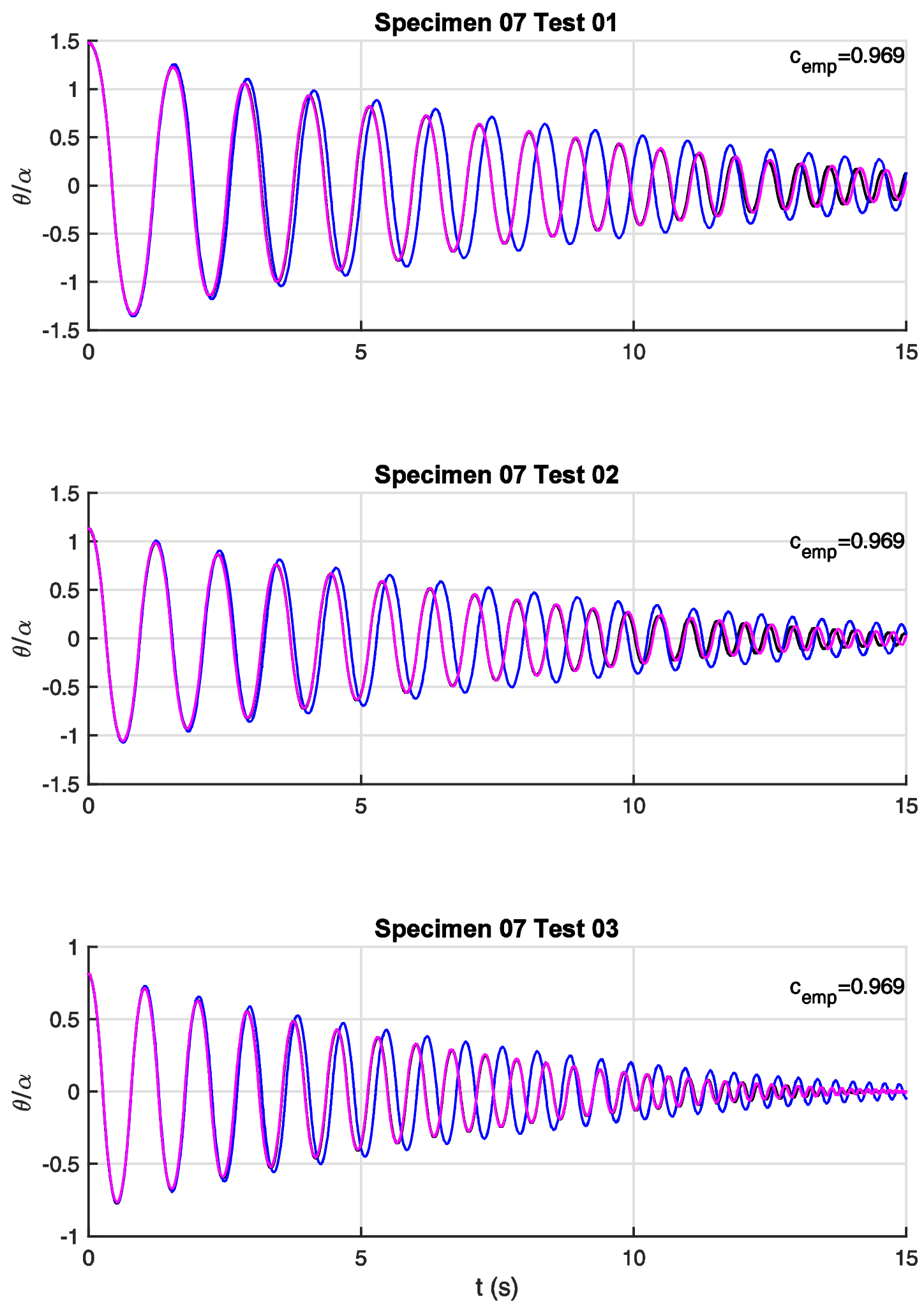

- Experimental $\longrightarrow$ Numerical (Housner) $\longrightarrow$ Numerical (empirical)

$\tan (\alpha)=0.15 \quad \tan \left(\alpha_{\mathrm{p}}\right)=0.3 \quad \rho=0.5 \quad \mathrm{I}_{\mathrm{c}}=265393 \mathrm{~kg} \mathrm{mm^{2 }} \quad \mathrm{m}=6.287 \mathrm{~kg} \quad \mathrm{c}_{\mathrm{th}}=0.973$

Figure 15. Normalized tilt angle, $\theta / \alpha$, time history for Specimen 7 

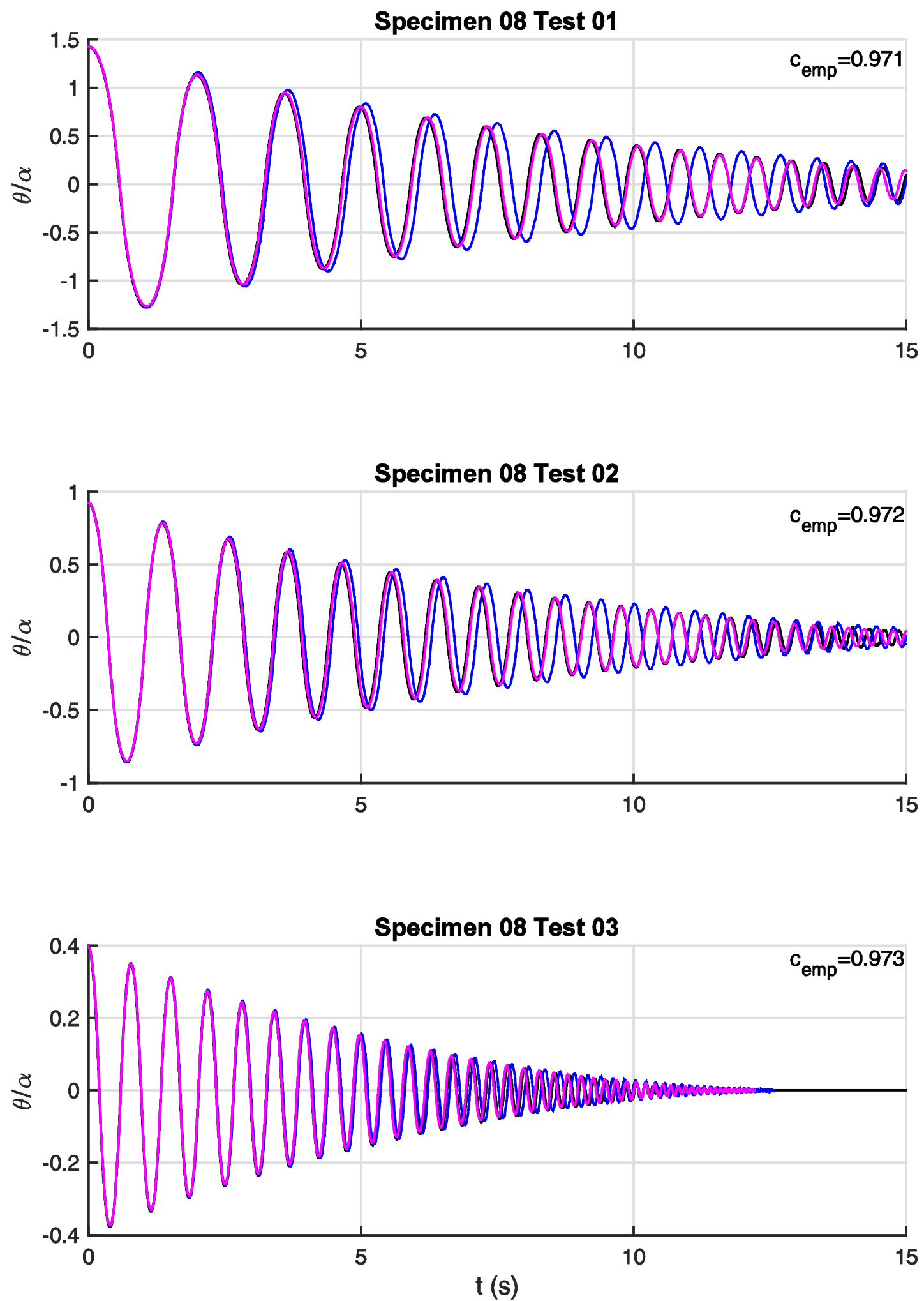

- Experimental — Numerical (Housner) — Numerical (empirical)

$\tan (\alpha)=0.15 \quad \tan \left(\alpha_{\mathrm{p}}\right)=0.3 \quad \rho=0.25 \quad \mathrm{I}_{\mathrm{c}}=261459 \mathrm{~kg} \mathrm{mm^{2 }} \quad \mathrm{m}=6.229 \mathrm{~kg} \quad \mathrm{c}_{\mathrm{th}}=0.973$

Figure 16. Normalized tilt angle, $\theta / \alpha$, time history for Specimen 8 


\section{REFERENCES}

[1] Housner, G. W. (1963). The behavior of inverted pendulum structures during earthquakes. Bulletin of the seismological society of America, 53(2), 403-417.

[2] Beck, J. L. and Skinner, R. I. (1973), The seismic response of a reinforced concrete bridge pier designed to step. Earthquake Engng. Struct. Dyn., 2: 343-358.

[3] Yim, C. S., Chopra, A. K., \& Penzien, J. (1980). Rocking response of rigid blocks to earthquakes. Earthquake Engineering \& Structural Dynamics, 8(6), 565-587.

[4] Psycharis, I. N. and Jennings, P. C. (1983), Rocking of slender rigid bodies allowed to uplift. Earthquake Engineering \& Structural Dynamics, 11: 57-76.

[5] Sharpe RD, Skinner RI, (1983) The seismic design of an industrial chimney with rocking base, Bulletin of the New Zealand National Society for Earthquake Engineering 16(2):98-106

[6] Chopra, A. K., \& Yim, S. C. S. (1985). Simplified earthquake analysis of structures with foundation uplift. Journal of Structural Engineering, 111(4), 906-930.

[7] Hogan, S. J. (1990). The many steady state responses of a rigid block under harmonic forcing. Earthquake Engineering \& Structural Dynamics, 19(7), 1057-1071.

[8] Psycharis, I. N. (1991). Effect of base uplift on dynamic response of SDOF structures. Journal of Structural Engineering, 117(3), 733-754.

[9] Makris, N., and Y. Roussos (1998). Rocking response and overturning of equipment under horizontal pulse-type motions, Rept. No. PEER-98/05, Pacific Earthquake Engineering Research Center, University of California, Berkeley, California.

[10] Zhang J, Makris N. (2001) Rocking response of free-standing blocks under cycloidal pulses. Journal of Engineering Mechanics, ASCE; 127(5):473-483.

[11] Makris, N. and Konstantinidis, D. (2003), The rocking spectrum and the limitations of practical design methodologies. Earthquake Engineering \& Structural Dynamics, 32, 265-289.

[12] Oliveto, G., Caliò, I. and Greco, A. (2003), Large displacement behaviour of a structural model with foundation uplift under impulsive and earthquake excitations. Earthquake Engng. Struct. Dyn., 32: 369-393.

[13] Prieto, F., Lourenço, P. B., \& Oliveira, C. S. (2004). Impulsive Dirac-delta forces in the rocking motion. Earthquake engineering \& structural dynamics, 33(7), 839-857.

[14] Konstantinidis, D., \& Makris, N. (2005). Seismic response analysis of multidrum classical columns. Earthquake engineering \& structural dynamics,34(10), 1243-1270.

[15] Apostolou M, Gazetas G, Garini E. (2007) Seismic response of slender rigid structures with foundation uplifting, Soil Dynamics and Earthquake Engineering, 27(7), 642-654

[16] Konstantinidis, D., \& Makris, N. (2007). The dynamics of a rocking block in three dimensions. In 8th Hellenic Society for Theoretical and Applied Mechanics International Congress on Mechanics.

[17] Peña, F., Prieto, F., Lourenço, P. B., Campos Costa, A., \& Lemos, J. V. (2007). On the dynamics of rocking motion of single rigid-block structures. Earthquake Engineering \& Structural Dynamics, 36(15), 2383-2399. 
[18] Ma, Q. T., \& Khan, M. H. (2008). Free vibration tests of a scale model of the South Rangitikei Railway Bridge. In Proceedings of the New Zealand Society for Earthquake Engineering Annual Conference, Engineering an Earthquake Resilient NZ.

[19] Contento, A., \& Di Egidio, A. (2009). Investigations into the benefits of base isolation for non-symmetric rigid blocks. Earthquake Engineering \& Structural Dynamics, 38(7), 849-866.

[20] Konstantinidis, D., \& Makris, N. (2009). Experimental and analytical studies on the response of freestanding laboratory equipment to earthquake shaking.Earthquake Engineering \& Structural Dynamics, 38(6), 827-848.

[21] Papaloizou, L., \& Komodromos, P. (2009). Planar investigation of the seismic response of ancient columns and colonnades with epistyles using a custom-made software. Soil Dynamics and Earthquake Engineering, 29(11), 1437-1454.

[22] Konstantinidis, D., \& Makris, N. (2010). Experimental and analytical studies on the response of 1/4-scale models of freestanding laboratory equipment subjected to strong earthquake shaking. Bulletin of earthquake engineering,8(6), 1457-1477.

[23] Ma, Q. T. M. (2010). The mechanics of rocking structures subjected to ground motion (Doctoral dissertation, ResearchSpace@ Auckland).

[24] Vassiliou, M. F. (2010). Analytical investigation of the dynamic response of a pair of columns capped with a rigid beam and of the effect of seismic isolation on rocking structures (Doctoral dissertation, Doctoral dissertation, Dept. of Civil Engineering, Univ. of Patras, Greece (in Greek)).

[25] ElGawady, M. A., Ma, Q., Butterworth, J. W., \& Ingham, J. (2011). Effects of interface material on the performance of free rocking blocks. Earthquake Engineering \& Structural Dynamics, 40(4), 375-392.

[26] Acikgoz, S., \& DeJong, M. J. (2012). The interaction of elasticity and rocking in flexible structures allowed to uplift. Earthquake Engineering \& Structural Dynamics, 41(15), 2177-2194.

[27] Dimitrakopoulos, E. G., \& DeJong, M. J. (2012). Revisiting the rocking block: closedform solutions and similarity laws. Proceedings of the Royal Society A: Mathematical, Physical and Engineering Science, 468(2144), 2294-2318.

[28] Dimitrakopoulos, E. G., \& DeJong, M. J. (2012). Overturning of retrofitted rocking structures under pulse-type excitations. Journal of engineering mechanics, 138(8), 963 972.

[29] Gelagoti, F., Kourkoulis, R., Anastasopoulos, I. and Gazetas, G. (2012), Rocking isolation of low-rise frame structures founded on isolated footings. Earthquake Engng. Struct. Dyn., 41: 1177-1197.

[30] Kourkoulis, R., Anastasopoulos, I., Gelagoti, F., \& Kokkali, P. (2012). Dimensional analysis of SDOF systems rocking on inelastic soil. Journal of Earthquake Engineering, 16(7), 995-1022.

[31] Makris, N., \& Vassiliou, M. F. (2012). Sizing the slenderness of free-standing rocking columns to withstand earthquake shaking. Archive of Applied Mechanics, 82(10-11), 1497-1511. 
[32] Vassiliou, M. F., \& Makris, N. (2012). Analysis of the rocking response of rigid blocks standing free on a seismically isolated base. Earthquake Engineering \& Structural Dynamics, 41(2), 177-196.

[33] Zulli, D., Contento, A., \& Di Egidio, A. (2012). 3D model of rigid block with a rectangular base subject to pulse-type excitation. International Journal of Non-Linear Mechanics, 47(6), 679-687.

[34] Acikgoz, S., \& DeJong, M. J. (2013), Analytical and experimental observations on vibration modes of flexible rocking structures, SECED - Society for Earthquake and Civil Engineering Dynamics Young Engineers Conference, July 4 ${ }^{\text {th }}, 2013$.

[35] Acikgoz, S., \& DeJong, M. J. (2013). Linearization and Modal Analysis of Flexible Rocking Structures. In Proceedings of NZSEE Conference.

[36] Antonellis, G., \& Panagiotou, M. (2013). Seismic Response of Bridges with Rocking Foundations Compared to Fixed-Base Bridges at a Near-Fault Site.Journal of Bridge Engineering, 19(5).

[37] Dimitrakopoulos, E. G., \& De Jong, M. J. (2013). Seismic overturning of rocking structures with external viscous dampers. In Computational methods in earthquake engineering (pp. 243-258). Springer Netherlands.

[38] Makris N. and Vassiliou M.F. (2013), Planar rocking response and stability analysis of an array of free standing columns capped with a freely supported rigid beam Earthquake Engng. Struct. Dyn, 42(3), 431-449.

[39] Sextos, A., Nalmpantis, S., Faraonis, P., Skiada, D., \& Stylianidis, K. (2013). Probabilistic seismic hazard assessment through geometrically non-linear back-analysis of byzantine and roman monuments. 10th HSTAM International Congress on Mechanics. Chania, Greece.

[40] Vassiliou, M. F., Mackie, K. R., \& Stojadinović, B. (2013). Rocking response of slender, flexible columns under pulse excitation. In Proceedings of the 4th ECCOMAS Thematic Conference on Computational Methods in Structural Dynamics and Earthquake Engineering, Kos Island, Greece (pp. 12-14).

[41] Zhang, H., Brogliato, B., \& Liu, C. (2013). Dynamics of planar rocking-blocks with Coulomb friction and unilateral constraints: comparisons between experimental and numerical data. Multibody System Dynamics, 1-25.

[42] Acikgoz, S., \& DeJong, M. J. (2014). The rocking response of large flexible structures to earthquakes. Bulletin of earthquake engineering, 12(2), 875-908.

[43] DeJong, M. J., \& Dimitrakopoulos, E. G. (2014). Dynamically equivalent rocking structures. Earthquake engineering \& structural dynamics, 43(10), 1543-1563.

[44] Drosos, V., \& Anastasopoulos, I. (2014). Shaking table testing of multidrum columns and portals. Earthquake Engineering \& Structural Dynamics, 43(11), 1703-1723.

[45] Makris, N. (2014). The Role of the Rotational Inertia on the Seismic Resistance of Free-Standing Rocking Columns and Articulated Frames. Bulletin of the Seismological Society of America.

[46] Makris, N., \& Vassiliou, M. F. (2014). Are Some Top-Heavy Structures More Stable?. Journal of Structural Engineering, 140(5). 
[47] Makris, N., \& Vassiliou, M. F. (2014). Dynamics of the rocking frame with vertical restrainers. Journal of Structural Engineering, 141(10), 04014245.

[48] Truniger, R., Vassiliou, M. F., \& Stojadinovic, B. (2014). Experimental study on the interaction between elasticity and rocking. In Proceedings of the 10th national conference in earthquake engineering, Earthquake Engineering Research Institute, Anchorage, AK.

[49] Vassiliou, M. F., Mackie, K. R., \& Stojadinović, B. (2014). Dynamic response analysis of solitary flexible rocking bodies: modeling and behavior under pulse-like ground excitation. Earthquake Engineering \& Structural Dynamics 43: 1463-1481

[50] Zhang, H., Brogliato, B., \& Liu, C. (2014). Dynamics of planar rocking-blocks with Coulomb friction and unilateral constraints: comparisons between experimental and numerical data. Multibody System Dynamics, 32(1), 1-25.

[51] Dimitrakopoulos, E. G., \& Giouvanidis, A. I. (2015). Seismic Response Analysis of the Planar Rocking Frame. Journal of Engineering Mechanics, 141(7), 04015003.

[52] Dimitrakopoulos, E. G., \& Paraskeva, T. S. (2015). Dimensionless fragility curves for rocking response to near-fault excitations. Earthquake Engineering \& Structural Dynamics, 44(12).

[53] Makris, N. "A Half-Century of Rocking Isolation" (2105) Earthquakes and Structures, Vol. 7, No 2, 2015

[54] Makris, N., \& Vassiliou, M. F. (2015). The dynamics of the rocking frame. In Seismic Assessment, Behavior and Retrofit of Heritage Buildings and Monuments (pp. 37-59). Springer International Publishing.

[55] Makris, N., \& Vassiliou, M. F. (2015). Seismic Response and Stability of the Rocking Frame. In Computational Methods, Seismic Protection, Hybrid Testing and Resilience in Earthquake Engineering (pp. 249-273). Springer International Publishing.

[56] Truniger, R., Vassiliou, M. F., \& Stojadinović, B. (2015). An analytical model of a deformable cantilever structure rocking on a rigid surface: experimental validation. Earthquake Engineering \& Structural Dynamics, 44(15), 2795-2815.

[57] Vassiliou, M. F., Mackie, K. R., \& Stojadinović, B. (2015) Earthquake response of deformable rocking frames Engineering Mechanics Institute Conference, Stanford, June 2015.

[58] Vassiliou, M. F., \& Makris, N. (2015). Dynamics of the Vertically Restrained Rocking Column. Journal of Engineering Mechanics, 141(12), 04015049.

[59] Vassiliou, M. F., Truniger, R., \& Stojadinović, B. (2015). An analytical model of a deformable cantilever structure rocking on a rigid surface: development and verification. Earthquake Engineering \& Structural Dynamics, 44(15), 2775-2794.

[60] Makris, N., \& Kampas, G. (2016). Size Versus Slenderness: Two Competing Parameters in the Seismic Stability of Free-Standing Rocking Columns. Bulletin of the Seismological Society of America.

[61] Bakhtiary, E., \& Gardoni, P. (2016). Probabilistic seismic demand model and fragility estimates for rocking symmetric blocks. Engineering Structures, 114, 25-34. 
[62] Pappas, A., da Porto, F., \& Modena, C. (2016). Seismic vulnerability assessment form for free-standing columns based on a simplified numerical analysis. International Journal of Architectural Heritage, (just-accepted).

[63] Eisenberg, J. M., \& Smirnov, V. I. Development of Earthquake Protection Structural Systems Based on Response Control. Proceedings of the 15th World Conference on Earthquake Engineering. Lisbon, Portugal.

[64] Papadopoulos C, DOMOS Engineers, Athens, Greece, personal communication, September 19, 2014

[65] Bachmann J., Vassiliou MF \& Stojadinovic B, (2015) Rocking of a rigid block on a curved foundation, Engineering Mechanics Institute Conference, Stanford, June 2015.

[66] Barthes, C. B. (2012). Design of Earthquake Resistant Bridges Using Rocking Columns. PhD Thesis, UC Berkeley, USA 